\title{
What is it like to be Out-of-Body? Phenomenal accounts of experiencers
}

\author{
Patrizio Tressoldi $^{1 *}$ and Luciano Pederzoli ${ }^{\S}$ \\ *Science of Consciousness Research Group, Studium Patavinum, Università di Padova, Italy \\ ${ }^{\S}$ EvanLab, Firenze, Italy
}

[final version available on https://www.qeios.com/read/WQ4GJA ]

\begin{abstract}
By using the descriptions of the Out-of-Body experiences of 13 participants, we aimed to have a picture of what it is like to be in this particular state of consciousness.

All information was grouped according to the following topics: consciousness status, selfboundaries, object perception, color perception, other types of perceptions, interactions with other people or beings, emotions, and time and movement perception.

From the 13 first-person accounts, it emerges a very different way to perceive and know with respect to the perception constrained by the brain and sensory organs.

Overall, the participants reported positive feelings, a consciousness status characterized by a high level of self-awareness without self-boundaries, and the ability to perceive information with almost all modalities, living in a timeless dimension.
\end{abstract}

Keywords: Out-of-Body; Consciousness; Phenomenology; Perception; Time; Idealism

\footnotetext{
${ }^{1}$ Corresponding author: Patrizio Tressoldi; email: patrizio.tressoldi@unipd.it
} 


\section{Introduction}

In order to have a more detailed description of "what it is like to be Out-of-Body", paraphrasing the title of the famous paper of Thomas Nagel "What Is It Like to Be a Bat?" (Nagel, 1974), it is necessary to know more about how out-of-body experiencers (OBErs) perceive and know during such experiences.

The peculiar characteristic of a typical out-of-body experience (OBE) is the subjective phenomenological first-person experience of being out of one's own body. In other words, a person in this state of consciousness perceives himself/herself out of his/her body. This is almost always seen as it was before having had such a type of experience, e.g., in the bed.

This experience can occur both after traumatic events, e.g. cardiac arrest, epileptic seizures (Blanke, Landis, Spinelli, \& Seeck, 2004; Greyson, Fountain, Derr, \& Broshek, 2014), spontaneously (Cardeña \& Alvarado, 2014) or induced after specific visual stimulations (Ehrsson, 2007) or practices, e.g. meditation (Wilde and Murray, 2009) and hypnosis (Facco et al., 2019; Pederzoli \& Tressoldi, 2018; Zeev-Wolf, Dor-Ziderman, Goldstein, Bonne, \& Abramowitz, 2017).

Surveys in the general population show that such a type of experience is not rare, ranging in frequency from $9 \%$ to $14 \%$ (Alvarado, 2015).

As expected, this type of experience has been attracting all of those who are interested in the relationship between mind/consciousness and the brain, because it raises the fundamental question: Is this type of experience a proof that the mind and consciousness can function separately from their biological substrate, the brain, or is a curious trick of the brain itself?

In order to settle such a question, it is necessary either to explain how the brain can generate such a strange experience or to demonstrate that when out-of-body (OB), participants can manifest perceptual or cognitive tasks that are incompatible with those observed when in the typical awake state of consciousness, for example perceiving objects or events bypassing the constraints of sensory organs.

Those interested in explaining how the brain can generate OBEs have been using data from brain-damaged participants and from neurophysiological correlates, e.g., magnetoencelography, EEG, and fMRI. At present, there is evidence that OBEs are associated with the functioning of the right hemisphere temporo-parietal junction, even if there are moderating effects of the participants' position before the experience and hence of vestibular and proprioceptive information, e.g., see Blanke \& Arzy, (2005), and Blanke, Faivre, \& Dieguez, (2016) using special visual stimulations in 
order to induce artificial OBEs, and Smith \& Messier, (2014), who studied a participant with voluntary OBEs.

However, finding an anatomical or a neurophysiological correlate of a mental experience does not explain its cause, unless postulating, as an axiom, that each mental experience is nothing but an expression or an emergent property of its neural correlate. Such a reasoning is analogous to inferring that TV programs are produced from the electronic circuits of the television because the damage or malfunctioning of these components impairs the quality of such programs.

Given the difficulties in studying persons having repeated spontaneous or voluntary OBEs, most of the phenomenological accounts available in the scientific literature are limited to participants having only a single OBE, and usually their phenomenological accounts are limited to how they perceive themselves or the relationship with the physical body, e.g., "I felt as if I had an invisible body", "I felt out of my body" (Bourdin et al., 2017).

Aim of this study is to know more about the perceptual and mental phenomenological experience when $\mathrm{OB}$, it is necessary to obtain first-person OBErs' accounts from those with multiple incidences of such experiences who have made available their phenomenological accounts.

\section{Methods}

\section{Participants}

By searching all possible extensive reports of people with recurrent or multiple OBEs from 2000 to 2022, first by using the keywords "repeated out-of-body" AND first-person, with the search engine scholar.google.com and by personal interactions with people interested in this topic, we retrieved 13 such reports. Seven reports were from people with spontaneous or voluntary OBEs and six were from people with OBEs induced by hypnotic suggestions (Tressoldi et al., 2015; Tressoldi $\&$ Pederzoli, 2021). Participants who reported OBEs after hypnotic suggestions were trained subjects with a long time of experience in this type of practice, as described by Pederzoli \& Tressoldi, (2018), which comprises a relaxation phase, and an OB induction phase with specific suggestions.

The participants' main demographic information, the OBEs method, and the bibliographic references related to their reports, are presented in Table 1. 
Table 1: Participants' demographic information and OBE method.

\begin{tabular}{|c|c|c|c|c|}
\hline Participant & Gender & Age & OBE method & Source \\
\hline $\mathrm{S}^{*}$ & M & 26 & hypnosis & $\begin{array}{l}\text { Tressoldi et al. } \\
(2014 ; 2015)\end{array}$ \\
\hline $\mathrm{Al}^{*}$ & $\mathrm{M}$ & 30 & hypnosis & idem \\
\hline $\mathrm{A}^{*}$ & $\mathrm{~F}$ & 32 & hypnosis & idem \\
\hline $\mathrm{F}^{*}$ & $\mathrm{~F}$ & 53 & hypnosis & idem \\
\hline $\mathrm{E}^{*}$ & $\mathrm{~F}$ & 41 & hypnosis & idem \\
\hline D* & $\mathrm{F}$ & 26 & hypnosis & idem \\
\hline $\mathrm{P}$ & M & 55 & $\begin{array}{l}\text { spontaneous } \\
\text { and self- } \\
\text { induced }\end{array}$ & Patelli (2022) \\
\hline GN & $\mathrm{M}$ & 45 & $\begin{array}{l}\text { spontaneous } \\
\text { and self- } \\
\text { induced }\end{array}$ & $\begin{array}{c}\text { Nicholls, } \\
\text { Pederzoli and } \\
\text { Tressoldi (2019) }\end{array}$ \\
\hline $\mathrm{C}$ & $\mathrm{M}$ & 54 & $\begin{array}{l}\text { spontaneous } \\
\text { and self- } \\
\text { induced }\end{array}$ & Melendez (2016) \\
\hline $\mathrm{M}$ & $\mathrm{M}$ & 50 & $\begin{array}{l}\text { spontaneous } \\
\text { and self- } \\
\text { induced }\end{array}$ & $\begin{array}{l}\text { Seller (2016; } \\
\text { 2017) }\end{array}$ \\
\hline $\mathrm{DJ}$ & $\mathrm{M}$ & 55 & $\begin{array}{l}\text { spontaneous } \\
\text { and self- } \\
\text { induced }\end{array}$ & Degracia (2004) \\
\hline CRJ & $\mathrm{M}$ & $\mathrm{n} / \mathrm{a}$ & $\begin{array}{l}\text { spontaneous } \\
\text { and self- } \\
\text { induced }\end{array}$ & Johnson (2016) \\
\hline $\mathrm{K}$ & $\mathrm{M}$ & $\mathrm{n} / \mathrm{a}$ & $\begin{array}{l}\text { spontaneous } \\
\text { and self- } \\
\text { induced }\end{array}$ & Kellogg (2016) \\
\hline
\end{tabular}

*= OBE induced by hypnotic suggestions 


\section{Procedure}

From their personal statements retrieved from the sources indicated in Table 1, we selected and copied verbatim all information related to how they perceived themselves and the environment in which they felt immersed. We used a classical qualitative Content Analysis inductive approach (Selvi, 2019), avoiding any interpretative approach.

All of this information was grouped in the aftermath according to the following topics: consciousness state, self-boundaries, object perception, color perceptions, other types of perceptions, interactions with other people or beings, emotions, time perception, and movement perception.

\section{Results}

\section{$\underline{\text { Consciousness state }}$}

Beatitude; I feel free (A*); Expanded; very pleasant (AL*); I feel very light; very well (D*); I'm pure awareness; It is a state of awareness $\left(\mathrm{F}^{*}\right)$; Like a thought $\left(\mathrm{S}^{*}\right)$; State of extreme lucidity and presence to myself (P); Clarity, expanded awareness, and beauty (GN); Your quantum of energy or consciousness pours into the space around you (M); Perhaps at first we continue to identify with ourselves as 'I', but after a time in the white space, there's not much for the ego to bounce off. When everything dissolves, what remains? When we spin a rainbow spinning-top, the colors merge into whiteness. When the rainbow of conscious experience merges into white light, self-perception and ego dissolve. What remains is lucid awareness (CRJ).

\section{$\underline{\text { Self-boundaries }}$}

I have an external point of view, but I cannot see my hands, feet, or body (A*); No, no boundaries (AL*, D*, S*); I feel totally free; I do not perceive boundaries or shapes (F*); You feel like you're in a voluminous space and you can't see anything around, you are away of the space, flowing, independently of the physical body, as a point of consciousness (C); I'm in whitish space, endless neutral light (CRJ); My OBE body generally seems a close counterpart to my physical body, stable in form, resistant to change, made of some sort of elastic semitransparent whitish material, that can feel either very light or very dense $(\mathrm{K})$. 


\section{$\underline{\text { Visual perception }}$}

Whatever I focus on is clear. Perfectly defined. Everything is more defined. I could perceive them simultaneously from all points of view $\left(\mathrm{A}^{*}\right)$; Less sharp, maybe because they are unimportant. I could see them from above, as if from the ceiling ( $\left.\mathrm{AL}^{*}\right)$; I was watching them from one point of view at a time, but I perceived them as a whole; I saw all aspects of them simultaneously (D*); At first, I see them from above as from a satellite, then if I zoom in on something I feel an attraction to it and I can then see all the details. I could see them any way I wanted, depending on my level of attention to them $\left(\mathrm{F}^{*}\right)$; Whatever I look at is well-defined and I see everything clearly, If I focused on them, I could see everything simultaneously; otherwise, only one side at a time ( $\left.\mathrm{S}^{*}\right)$; I have a better sense of space and volume. (E*); Everything is in focus. I can even see things from the inside - I can feel their consistency and can feel what they are made of (D*); Zooming the visual field results in unusually close-up and detailed perception. Sometimes a 360-degree vision (GN); You can see from all directions at once, able to perceive with 360-degree vision (M); Upon separation, the room appeared to me just the same with normal eyesight. But it was only a good year and a half or so later that I was able to see things that I normally couldn't see - and these are just things hidden by location (C).

\section{$\underline{\text { Color perception }}$}

Brighter, clearer. (A*); Some colors are very bright, others faded. They are more intense than in the physical body $\left(\mathrm{F}^{*}\right)$; I see them very well, but they are fuller and independent of surrounding light. The colors of what I focus on are clear but seem different from the real ones. I see colors like in the physical body, but all are brighter and with no shadows $\left(\mathrm{S}^{*}\right)$; They [colors] are purer, but I see everything superimposed. It looks blurred. Clear but intense, fuller than with the physical body ( $\left.\mathrm{D}^{*}\right)$; The profusion of shades and the glitter of the colorations is such that nothing similar is given to see on Earth, not even in certain shining spring days in the spring days when the sun shines on our valleys. These, if taken as a comparison, express only a pale, washed-out reflection $(\mathrm{P})$; At this high level, everything was way more alive and vibrant in optimum condition. I was mesmerised simply by the color of the grass for what felt like maybe twenty minutes (C); I find it difficult to see them; everything seems black and white (E).

\section{Other types of perceptions}

The most common forms of exteroception were temperature, touch and "texture" perception. Auditory sensations were apparent in $72 \%$ of the experiences (GN); I can smell different aromas 
and taste different tastes, even if I am not eating anything. You can feel the shape of objects at a distance. Hear what is happening in the distance (M); I was able to touch objects at distance. I don't have to physically see the object to know what it is. I just feel it with my extended consciousness. When listening to music, I perceive the color of it "as each sound has its own color." (C);

\section{Interactions with other people or beings}

The person I am trying to communicate with will simultaneously ignore me on a physical level but engage me telepathically to say that he is busy and cannot talk; ... in communicating this rather strange phrase (remember that when I say talk, I mean telepathic conversation ... (P); Information is instant telepathic thought (M); I am only using this entry to illustrate that there seemed to be telepathy between me and the rhino (DJ);

\section{$\underline{\text { Emotions }}$}

I feel lighter. I can sense feelings and emotions (AL*); Emotions are experienced in a much more intense and strong way than in the physical and it is necessary to pay particular attention not to be overwhelmed (P); I would not use the term emotion, it is more an attraction for something or other. Emotions belong to the psychical body, as long as it is attached to the physical body $\left(\mathrm{F}^{*}\right)$; I do not really feel emotions. Emotions are for the physical body and consciousness ( $\left.\mathrm{S}^{*}\right)$; They are not real emotions, they are lighter, and I can feel them all together, but not in their fullness. I can sense them but there is no need to $\left(\mathrm{D}^{*}\right)$.

\section{$\underline{\text { Time perception }}$}

I didn't have any sense of time (A*); I felt no sense of time traveling to Padova; I could sense it while moving around the room and while watching the objects as if I were in my physical body $\left(\mathrm{AL}^{*}, \mathrm{~S}^{*}\right)$; I did not experience it while moving from one place to another; while watching an object I realized time was passing, but I had no sense of time (D*); Not at all; I was aware of the succession of events, but not of time. I could sense time if I moved slowly $\left(\mathrm{F}^{*}\right)$; There is no perception of the passage of time (P); Very little perception of time. In $10 \%$ of the experiences, a movement forwards or backwards within "some form of time" (GN); In the OBE state, neither time nor space exists. I discovered that the past, as such, is not fixed; it can be changed because it does not exist separately. It is a part of the present, as is the future, so both could be changed with intense feeling-based intention directed at whatever you wish to change (M) 


\section{Movement perception}

I will it $\left(\mathrm{A}^{*}\right)$; I am horizontal. I feel like I am rolling. Almost like crawling. I can move at will a body which seems almost gelatinous (AL*); A bit like zooming in immediately (D*); I intend it and I get there in zero time $\left(\mathrm{F}^{*}\right)$; I fly. I simply have the thought and I can do it ( $\left.\mathrm{S}^{*}\right)$; I fly. I can initiate motion with my intention. I am light and I can go through everything (D*); Instantaneous movement in the majority of cases, e.g. "Once the flowing sensations running through my body subsided, I simply found myself at a very tall building, which appeared to be in London" (GN); There was no sense of travelling the 10 miles from my house to his room; it was instant, exactly like an edit on a film (C); I seemed to be floating, without legs or feet. Movement seemed to result simply from me thinking of moving (DJ).

\section{$\underline{\text { Results synthesis }}$}

\section{$\underline{\text { Self -boundaries }}$}

The most common characteristic is to exist with no boundaries, highlighting a kind of paradox of a defined and distinct Self without boundaries, similar to a physical particle without mass, like photons.

In one case, participant $\mathrm{K}$ described a sort of semi-transparent whitish body, that could be felt as being either very light or very dense. This sort of body is similar to the descriptions of the etheric or subtle body experienced in the initial phases of OBEs (Tressoldi et al., 2015)

\section{$\underline{\text { Visual perception }}$}

A general characteristic is that object perception is not constrained by the characteristics and functionality of the visual system as expected. It is described as a sort of mental perception where it is possible to see the target from all points of view simultaneously and to zoom in or out on the details depending on the interest of the perceiver.

\section{Color perception}

Most participants describe color perception as characterized by more vivid and brighter colors that seem to derive from a sort of energy within the objects and not as a reflection of an external light. However, a minority (E) perceives colors as only black and white. 


\section{Other types of perceptions}

Smell, taste, auditory and tactile perceptions seem available even if in some cases they seem synesthetically related. Even in this case, these perceptions are not constrained by the characteristics of the sensory apparatuses as expected.

$\underline{\text { Interactions with other people or beings }}$

It seems that the exchange of information is based only on telepathic means without using language.

\section{$\underline{\text { Emotions }}$}

Some participants report having emotions and feelings, but their valence and intensity are not similar to those experienced in the physical body. On the contrary, others (F, S, D) report no emotion at all.

\section{$\underline{\text { Time perception }}$}

The main characteristic is that there is no perception of time in the OB even if there are perceptions of changes in experiences, which seems to be a contradiction. The OBEs are described as multiple experiences in a timeless dimension.

\section{$\underline{\text { Movement perception }}$}

In general, there is no perception of movement, but only a change in place after a simple wish or intention. It seems then that there is no movement in the space as perceived in the physical body.

\section{Discussion}

While waiting to have a larger sample of such a type of participants, possibly interviewed with a common structured procedure, with all its limitations, this sample of participants with recurrent or multiple OBEs offers a wide description of the "phenomenological world" experienced when OB. Different from most of the previous accounts reported in the scientific literature, this study allows us to have a more expanded, even if not complete, idea of "what is like to be OB".

Certainly, OBErs describe a "strange" reality, strange with respect to our everyday one, obviously.

The descriptions of how our participants perceive and know look very similar to those reported by near-death experiencers, as reported by Jourdan and Smythies (2019). For example, 
their participants reported to be able to perceive objects from any direction, a " $360^{\circ}$ vision", see what they want even if masked by other objects, be able to zoom in and out depending on what they want to see.

But how can we prove that this reality exists apart from the convergent descriptions of those who have had this type of conscious experience? Furthermore, if this other reality exists, is it independent from our ordinary one, or do they interact with each other? In other words, can OBErs interact with the ordinary reality? In order to respond to such questions, it is necessary to devise experiments where OBErs are requested to perform tasks that can be verified in our ordinary reality by third-person witnesses.

The number of OB experimental veridical accounts is not high, but there are some. For example, Paquette (2012) described a series of personal verified OBE. Furthermore, Ballati, Prati, Pederzoli, \& Tressoldi (2020) and Tressoldi \& Pederzoli (2021), devised two different experimental procedures in order to verify whether OBErs were able to use their perceptual and cognitive skills to obtain information at a distance without any possibility to use conventional means. In Tressoldi and Pederzoli (2021), five selected participants, after being induced into an OB state of consciousness by using the hypnotic procedure described by Pederzoli \& Tressoldi (2018), were requested to identify images located in rooms hundreds of kilometers away from their location. Participants correctly identified $46.7 \%$ of images, well above the chance rate of $25 \%$.

Ballati et al. (2020) instead, requested four selected participants to describe five different and unknown buildings located hundreds of kilometers away from their location, after being induced into $\mathrm{OB}$ by using the same procedures. Participants were able to provide $55 \%$ of the correct information.

From the results of these two studies, it seems that some participants can apply the perceptual characteristics of the $\mathrm{OB}$ condition to our typical reality, showing that a connection between these two realities is possible. If this interpretation holds, it suggests that humans can use both the perceptual and cognitive skills of an $\mathrm{OB}$ and a typical everyday condition simply by changing their state of consciousness.

Waiting for a demonstration of how more or less complex bioelectrical signals can give rise to $\mathrm{OB}$ phenomenological experiences, an alternative hypothesis is that $\mathrm{OB}$ phenomenological experiences derive from consciousness contents, considered primary, interacting with the brain and bypassing the sensory organs that in our everyday awake embodied experience act as special filters or an interface, with what we consider external reality. 
Without such "sensory organs' special devices" we can have different experiences and probably a more direct hint of "who we really are" in agreement with some philosophical traditions like Idealism (Kastrup, 2018), Dual-aspect monism (Walach, 2020) and Non-duality (Indich, 1995; Sedlmeier \& Srinivas, 2016). 


\section{Acknowledgments}

We acknowledge the English revision by the Proof-Reading Service and Queios.

This version 2, was revised taking in account the comments and suggestions of the reviewers Marc

Wittmann, Renaud Evraud, Marcelo Saad, Andrew Paquette and Ingrid Egerod 


\section{References}

Alvarado, C. S. (2015). Out-of-Body Experience (OBE). Psi Encyclopedia. London: The Society for Psychical Research. https://psi-encyclopedia.spr.ac.uk/articles/out-body-experience-obe . Retrieved 12 July 2021.

Ballati, A., Prati, E., Pederzoli, L., \& Tressoldi, P. (2020). Remote Viewing with and without controlled Out-Of-Body Consciousness. Advanced Research in Psychology, 14154. https://doi.org/10.46412/001C.14154

Blanke, O., \& Arzy, S. (2005). The out-of-body experience: disturbed self-processing at the temporo-parietal junction. The Neuroscientist : A Review Journal Bringing Neurobiology, Neurology and Psychiatry, 11(1), 16-24. https://doi.org/10.1177/1073858404270885

Blanke, O., Faivre, N., \& Dieguez, S. (2016). Leaving Body and Life Behind: Out-of-Body and Near-Death Experience. In The Neurology of Consciousness (pp. 323-347). Academic Press. https://doi.org/10.1016/B978-0-12-800948-2.00020-0

Blanke, O., Landis, T., Spinelli, L., \& Seeck, M. (2004). Out-of-body experience and autoscopy of neurological origin. Brain, 127(2), 243-258. https://doi.org/10.1093/brain/awh040

Bourdin, P., Barberia, I., Oliva, R., Slater, M. (2017). A Virtual Out-of-Body Experience Reduces Fear of Death. PLOS ONE, 12(1), e0169343. https://doi.org/10.1371/journal.pone.0169343

Cardeña, E., \& Alvarado, C. S. (2014). Anomalous self and identity experiences. In Varieties of anomalous experience: Examining the scientific evidence (2nd ed.). (pp. 175-212). https://doi.org/10.1037/14258-007

Degracia, D. J. (1994). DO_OBE. Retrieved from http://files.abovetopsecret.com/files/55329b5fb382cf64.pdf

Ehrsson, H. H. (2007). The Experimental Induction of Out-of-Body Experiences. Science, 317(5841), 1048. https://doi.org/10.1126/science.1142175

Facco, E., Casiglia, E., Al Khafaji, B. E. B. E., Finatti, F., Duma, G. M. G. M. M., Mento, G., ... Tressoldi, P. (2019). The neurophenomenology of Out-of-Body experiences induced by hypnotic suggestions. Internation Journal of Clinical and Experimental Hypnosis, 67(1), 3968. https://doi.org/10.1080/00207144.2019.1553762

Greyson, B., Fountain, N. B., Derr, L. L., \& Broshek, D. K. (2014). Out-of-body experiences 
associated with seizures. Front Hum.Neurosci., 8(1662-5161 (Electronic)), 65.

Jourdan,JP \& Smythies, J. (2019). An exploratory study of perceptual and cognitive features in near-death experiences: A proposed model and research recommendations. Journal of Near-Death Studies, 37, 2.

Indich, W. M. (1995). Consciousness in Advaita Vedanta. Motilal Banarsidass Publ. New Delhi, India

Johnson, C. R. (2016). Surfing the Rainbow: Fearless and Creative Out-of-Body Experiences. In Alexander De Foe (Ed). Consciousness beyond the body evidence and reflections. Melbourne Centre for Exceptional Human Potential. Retrieved from https://deepluciddreaming.com/wpcontent/uploads/2016/02/Dr-Clare-Johnson-SURFING-THE-RAINBOW.pdf

Josipovic, Z. (2019). Nondual awareness: Consciousness-as-such as non-representational reflexivity. In Progress in Brain Research (Vol. 244, pp. 273-298). Elsevier B.V. https://doi.org/10.1016/bs.pbr.2018.10.021

Kastrup, B. (2018). The universe in consciousness. Journal of Consciousness Studies, 25(5-6), 125155.

Kellogg, E. (2016). Out-of-Body experiences and lucid dreams: a phenomenological approach. In Alexander De Foe (Ed). Consciousness beyond the body evidence and reflections. Melbourne Centre for Exceptional Human Potential. Retrieved from https://www.academia.edu/download/42582327/OBELD-ch3CBB-Kellogg.pdf

Melendez, L. (2016). "There is nothing to fear about dying. This Earth is not our home and what lies beyond is marvellous." An IPA exploration of the out-of-body experience-single participant case study (Doctoral dissertation, University of Northampton). Retrieved from https://www.academia.edu/download/62989740/out-of-body-experiencedissertation_luis_melendez20200417-67421-14vdcyb.pdf

Nagel, T. (1974). What is it like to be a bat? The Philosophical Review, 83(4), 435-450.

Nicholls, G., Pederzoli, L., \& Tressoldi, P. (2019). The phenomenology of spontaneous and hypnotically induced Out-of-Body Experiences: A comparison. MindRxiv https://mindrxiv.org/pqcer 
Paquette, A. (2012). NDE implications from a group of spontaneous long-distance veridical OBEs. Journal of Scientific Exploration, 26(4), 791.

Patelli, R. (2022). Autobiografia di un viaggiatore astrale. [Autobiography of an astral traveler] Le due Torri, Bologna, Italy

Pederzoli, L., \& Tressoldi, P. E. (2018). A Guide for OBE Induction. SSRN Electronic Journal. https://doi.org/10.2139/SSRN.3148432

Sedlmeier, P., \& Srinivas, K. (2016). How do theories of cognition and consciousness in ancient Indian thought systems relate to current Western theorizing and research?. Frontiers in Psychology, 7, 343; https://doi.org/10.3389/fpsyg.2016.00343

Seller, J. (2016). Out-of-body Multidimensional Journeys. In Rodwell, M. (Ed) The New Human: Awakening to Our Cosmic Heritage. New Mind Publishers.

Sellers, J. (2017). Out-of-Body Experience: Review \& a Case Study. Journal of Consciousness Exploration \& Research, 8(9), 686-708.

Selvi, A. F. (2019). Qualitative content analysis. In The Routledge handbook of research methods in applied linguistics (pp. 440-452). Routledge.

Smith, A. M., \& Messier, C. (2014). Voluntary Out-of-Body Experience: An fMRI Study. Frontiers in Human Neuroscience, 8, 70. https://doi.org/10.3389/fnhum.2014.00070

Tressoldi, P. E., Pederzoli, L., Caini, P., Ferrini, A., Melloni, S., Prati, E., ... Trabucco, A. (2015). Hypnotically Induced Out-of-Body Experience: How Many Bodies Are There? Unexpected Discoveries About the Subtle Body and Psychic Body. SAGE Open, 5(4). https://doi.org/10.1177/2158244015615919

Tressoldi, P., \& Pederzoli, L. (2014). Out-of-Body Experience induced by hypnotic suggestion: phenomenology and perceptual characteristics. MindRxiv, https://mindrxiv.org/pqcer

Walach, H. (2020). Inner experience-direct access to reality: a complementarist ontology and dual aspect monism support a broader epistemology. Frontiers in Psychology, 11, 640. doi: 10.3389/fpsyg.2020.00640

Wilde, D., \& Murray, C. D. (2009). An interpretative phenomenological analysis of out-of-body experiences in two cases of novice meditators. Australian Journal of Clinical and Experimental Hypnosis, 37(2), 90-118. 
Zeev-Wolf, M., Dor-Ziderman, Y., Goldstein, A., Bonne, O., \& Abramowitz, E. G. (2017).

Oscillatory brain mechanisms of the hypnotically-induced out-of-body experience. Cortex, 96, 19-30. https://doi.org/10.1016/j.cortex.2017.08.025 